\title{
Gini Katsayısını Etkileyen Faktörlerin Beta Regresyon Yöntemi Yardımı ile Belirlenmesi
}

\author{
Tolga ZAMAN*1므, Emre DÜNDER ${ }^{2}$, Serpil AYDIN ${ }^{2}$ \\ ${ }^{1}$ Çankırı Karatekin Üniversitesi, Fen Fakültesi, İstatistik Bölümü, 18100, Çankırı, Türkiye \\ ${ }^{2}$ Ondokuz Mayıs Üniversitesi, Fen Edebiyat Fakültesi, İstatistik Bölümü, 55139, Samsun, Türkiye
}

Geliş / Received: 12/07/2018, Kabul / Accepted: 08/03/2019

\begin{abstract}
Öz
$\mathrm{Bu}$ çalışmanın amacı bazı gelişmiş ve gelişmekte olan ülkelere ait, Gini katsayısı üzerinde etkisi olan makroekonomik değişkenleri belirlemektir. Bir ülkede milli gelirin dağılımının eşit olup olmadığını ölçmeye yarayan Gini Katsayısı, 0 ila 1sayıları arasında değerler alır. Çalışmada bağımlı değişken olan Gini katsayısı 01 aralığında oransal değerler aldığı için modelleme aşamasında Beta Regresyon Analizi uygulanmıştır. Analiz sonuçlarına göre ilgilenilen ülkelerin Gini katsayıları üzerinde anlamlı etkisi bulunan değişkenler tespit edilip, çeşitli yorumlamalar yapılmıştır. Analiz R programlama dili yardımıyla gerçekleştirilmiştir.
\end{abstract}

Anahtar Kelimeler: Beta regresyon, Gini katsayısı, Gelir eşitsizliği, Ekonomik değişkenler, Ülkeler.

Determining the Factors that Influence Gini Coefficient by Beta Regression Method

\begin{abstract}
The purpose of this study is to identify the macroeconomic variables of some developed and developing countries that have an impact on the Gini coefficient. The Gini Coefficient, which measures the distribution of income in a country, is between 0 and 1. Beta Regression Analysis was applied at the modeling stage since the Gini coefficient, which is dependent variable in the study, received the proportional values on the interval 0-1. According to the results of the analysis, the variables that have a significant effect on the Gini coefficients of the countries concerned were determined and various interpretations were made. The analysis was performed with the aid of the $\mathrm{R}$ programming language.
\end{abstract}

Keywords: Beta regression, Gini coefficient, Income inequality, Economic variables, Countries.

\section{Giriș}

Günümüzde gelir dağılımı bütün ülkelerin gündeminde olan ortak bir konudur. Özelikle 20 'nci yüzyılın sonlarına doğru daha da önemli hale gelen küreselleşme ile birlikte belirginleşen gelir dağılımı, eşitsizliği ve bu eşitsizlik ile artan yoksulluğu (World Bank, 2000) çözülmesi gereken bir problem haline getirmiştir. $\mathrm{Bu}$ eşitsizlik sorunu tüm toplumlarda farklı yoğunluklarda görülmektedir. Eşitsizlik, her insana farklı davranmak demektir. Burada eşitsizlik, ister gelirde, ister tüketimde ya da bir toplumun gösterge veya tutumlarındaki farklılıklarında olsun, bölüşüm dengesizliği olarak ifade edilebilir. Pratikte ortaya çıkan bu farklı tutumların, özel bir ödüllendirme sistemi gibi etik kavramları içerip içermediği ve birçok tartışmaya referans olan gelir farklılıklarını ifade etmenin bir metodu olduğu tartışılabilir (Atkinson, 1983; Sen, 1973). Gelir eşitsizliği konusunda sıklıkla kullanılan Gini katsayısı, toplum içerisindeki gelir dağılımındaki eşitsizliği ölçmeye yarayan bir oran olarak İtalyan istatistikçi Corrado Gini tarafından 1912'de geliştirilmiş bir katsayıdır (Bronfenbrenner, 1971). Yani, Gini katsayıs1 özetleyici bir eşitsizlik katsayısıdır ve Lorenz eğrisi ile basitçe ifade edilebilen bir ilişkiye 
sahiptir. 0 ila 1 sayıları arasında değerler alan Gini katsayısının yüksek değerler alması daha yüksek bir eşitsizlik oranına denk düşer. Küçülmesi ise gelir dağılımı eşitsizliğinde bir azalmayı ve gelir dağılımında gerçekleşen bir düzelmeyi gösterir (DPT, 1994). Bir ülkede herkesin eşit gelire sahip olduğunu düşünürsek, Gini katsayısı sıfıra eşittir. Tüm gelirin sadece bir kişide toplandığını varsayarsak, Gini katsayısı 1'e eşit olur. Başka bir ifade ile Gini katsayısı arttıkça eşitsizlik de artmaktadır. Lorenz eğrisine bağlı olan Gini katsayısı, Lorenz ve köşegen arasında kalan alanın, köşegenin altında kalan toplam alana oranına tekabül eder. Literatürde Gini katsayısını içeren bazı önemli çalışmalar şu şekildedir. Carter (2006) çalışmasında ekonomik özgürlüklerin Gini katsayısını arttırdığı sonucuna varmıştır. Ekonomik özgürlükler gelir elde edilmesinde çeşitli firsatlar sağladığından özellikle toplumdaki fakirler aleyhine gelir dağılımının bozulmasına neden olmaktadır. Li vd. (2000) çalışmasında yolsuzluk ve Gini katsayısı arasında kuadratik bir ilişki tespit etmiş ve orta düzeyde yolsuzluk olan ülkelerde Gini katsayısı en yüksek değere, düşük ve yüksek yolsuzluk oranlarının olduğu ülkelerde Gini katsayısı ise daha düşük değere sahip olduğu sonucuna varmıştır. Chong ve Calderon (2000) çalışmasında kurumsal kalite ile Gini katsayısı arasında kuadratik bir ilişki tespit etmiştir. Özellikle kurumsal kalitesi daha iyi olan ülkelerde kurumsal kalite ile Gini katsayısı arasında negatif bir ilişki söz konusu iken kurumsal kalitesi düşük olan ülkelerde ise değişkenler arasında pozitif bir ilişki söz konusudur. Barro (2000) çalışmasında hukuk ve düzen ile Gini katsayısı arasındaki ilişkiyi incelemiş ve değişkenler arasında negatif bir ilişki olduğu sonucuna varmıştır. Birçok araştırma alanında, bağımlı değişkenin standart birim aralığında $(0,1)$ değer alması oldukça yaygındır. Doğrusal regresyon modeli bu tür bir bağımlı değişkene uygulandığında bazı dezavantajlar vardır. $\mathrm{Bu}$ sorunun üstesinden gelmek için, Cribari-Neto ve Souza (2012) çalışmasında bağımlı değişkenin beta dağılışı olduğu varsayımına dayanan bir beta regresyon modeli ortaya koymuştur. Onlar, McCullagh vd. (1989) tarafından sunulan Genelleştirilmiş doğrusal modeller formunda modelleme ve çıkarım yöntemlerini kullandılar. Beta regresyon modelleri tıp, orman bilimi, eğitim, ekonomi ve siyaset bilimi gibi birçok alanda sıklıkla kullanılmaktadır. Smithson ve Verkuilen (2006) çalışmasında doğrusal regresyon kullanılarak beta regresyondaki ortalama ve kesinlik parametrelerini modellediler. Simas vd. (2010) çalışmasında beta regresyonda ortalama ve kesinlik parametrelerini tahmin etmek için doğrusal ya da doğrusal olmayan regresyon kullandilar. Ospina ve Ferrari (2012) çalışmasında aşırı değerleri modellemek için dejenere dağılımları kullanarak beta regresyon modelleri önermişlerdir. $\mathrm{Bu}$ çalışmada, gelişmiş ve gelişmekte olan 63 ülke gelirleri arasındaki farklılıkların nedenleri, Gayrı safi milli hasıla, Elektriğe erişim, Doğrudan yabancı yatırım, Enflasyon, Vergi geliri, İşsizlik, Hükümetin eğitim harcamaları gibi makroekonomik değişkenlerin birbirleri ile ilişkileri beta regresyon analizi yöntemiyle belirlenmiştir.

\section{Beta Regresyon}

Bağımlı değişkenin değer aralığı $(0,1)$ aralığında yer aldığı durumlarda, klasik lineer regresyon analizi uygulanamaz. Bu durumda verinin doğasına uygun olarak beta regresyon analizi kullanılır (Ferrari and Cribari-Neto, 2004). Beta dağılımı için olasılık yoğunluk fonksiyonu

$\mathrm{f}(\mathrm{y} \mid \mu, \delta)=\frac{\Gamma(\delta)}{\Gamma(\mu \delta) \Gamma((1-\mu) \delta)} \mathrm{y}^{(\mu \delta-1)}(1-\mathrm{y})^{(1-\mu) \delta-1}$
$0<y<1$

biçiminde tanımlanır. Eşitlik 1'de yer alan $\mu$ konum parametresini, ve $\delta$ ise yayilım parametresini ifade etmektedir. Beta dağılımına uygun olan y değişkeninin beklenen değeri $E(y)=\mu$, varyansın da 
$\operatorname{Var}(\mathrm{y})=\mu(1-\mu) /(1+\delta) \quad$ biçimindedir (Zhao vd., 2014). Beta regresyon modeli g(.) bağ fonksiyonu ile

$g(\mu)=\sum_{p=1}^{p} \beta_{i k} X_{i k}$

şeklinde tanımlanır. Eşitlik 2'den hareketle beta regresyon modeli, beta dağılımı ile oluşturulan log-olabilirlik fonksiyonu kullanılarak oluşturulur. Beta regresyon modeli için elde edilen log-olabilirlik fonksiyonu

$L(\mu, \delta)=\log \Gamma(\delta)-\log \Gamma(\mu \delta)-\log \Gamma((1-\mu) \delta)+$ $(\mu \delta-1) \log y+((1-\mu) \delta-1) \log (1-y)$

şeklindedir. Log-olabilirlik fonksiyonunun değerini maksimum yapacak olan en çok olabilirlik tahminleri hesaplanarak regresyon katsayıları elde edilir. Bu hesaplama süreci nümerik analiz tekniklerinden NewtonRaphson veya Fisher skorlama algoritmaları ile gerçekleştirilebilir (Zhao vd., 2014).

\section{Uygulama}

Çalışmada kullanılan veriler The World Bank Databank (Anonim, 2017) internet sitesinde bulunan 63 ülke için derlenmiştir. Bu ülkeler aşağıdaki gibidir.

Belçika, Bulgaristan, Çek Cumhuriyeti, Danimarka, Almanya, Estonya, İrlanda, Yunanistan, İspanya, Fransa, Hirvatistan, İtalya, Kibris, Letonya, Litvanya, Lüksemburg, Macaristan, Malta, Hollanda, Avusturya, Polonya, Portekiz, Romanya, Slovenya, Slovakya, Finlandiya, İsveç, Birleşik Krallık, İzlanda, Norveç, İsviçre, Makedonya, Surbistan, Türkiye, Arjantin, Ermenistan, Beyaz Rusya, Bolivya, Brezilya, Burkina Faso, Kamerun, Kolombiya, Kosta Rika, Ekvator, El Salvador, Gürcistan, Guatemala, Honduras, Kirgizistan Cumhuriyeti, Moritanya, Meksika, Moldova, Moğolistan, Karadağ, Nikaragua, Nijer, Panama, Paraguay, Peru, Tacikistan, Ukrayna, Uruguay, Vietnam.
Tablo 1. Veri setine ait değiş̧kenler ve kısaltmaları.

\begin{tabular}{ll}
\hline Değişken & Kısaltma \\
\hline Gayrı safi milli hasıla & GSMH \\
Elektriğe erişim & EE \\
Doğrudan yabancı yatırım & DYY \\
Enflasyon & ENF \\
Vergi geliri & VG \\
İşsizlik & İŞZ \\
Hükümetin eğitim harcamaları & HEH \\
\hline
\end{tabular}

Tablo1' de analizler için kullanılan yedi adet makro ekonomik değişkenlerin tanımları ve kısaltmaları yer almaktadır.

Tablo 2' de veri setinde yer alan makro ekonomik değişkenler arasındaki korelasyon matrisi gösterilmektedir. Korelasyon matrisine göre bağımlı değişken GİNI katsayısı ile GSMH, EE, VG ve İşZ değişkenleri arasında istatistiksel olarak anlamlı bir ilişki vardır $(\mathrm{p}<0.05)$. Bu sonuca göre GINII katsayısı bağımlı değişken olarak alınarak bir regresyon modeli oluşturulabilir. Ayrıca korelasyon matrisine göre bağımsız değişkenler arasında çoklu bağlantı problemine yol açacak düzeyde yüksek ilişki yoktur. 
Tablo 2. Korelasyon matrisi.

\begin{tabular}{|c|c|c|c|c|c|c|c|c|}
\hline & & GINİ & GSMH & EE & DYY & ENF & VG & İŞZ \\
\hline \multirow{2}{*}{ GINII } & Korelasyon & 1.0 & $.287 *$ & $-.52 * *$ & -.08 & .204 & $-.314 *$ & $-.422 * *$ \\
\hline & $\mathrm{p}$ & . & .023 & .000 & .532 & .110 & .012 & .001 \\
\hline \multirow{2}{*}{ GSMH } & Korelasyon & $.287 *$ & 1.000 & $-.40 * *$ & $-.321 *$ & $.437 * *$ & -.167 & $-.083^{*}$ \\
\hline & $\mathrm{p}$ & .023 & . & .001 & .010 & .000 & .190 & .517 \\
\hline \multirow{2}{*}{$\mathrm{EE}$} & Korelasyon & $-.52 * *$ & $-.40 * *$ & 1.0 & $.279^{*}$ & $-.282 *$ & .106 & .225 \\
\hline & $\mathrm{p}$ & .000 & .001 & . & .027 & .025 & .407 & .076 \\
\hline \multirow{2}{*}{ DYY } & Korelasyon & -.080 & $-.321 *$ & $.279^{*}$ & 1.000 & -.199 & -.031 & .051 \\
\hline & $\mathrm{p}$ & .532 & .010 & .027 & . & .118 & .810 & .693 \\
\hline \multirow{2}{*}{ ENF } & Korelasyon & .204 & $.437 * *$ & $-.282 *$ & -.199 & 1.000 & -.101 & -.104 \\
\hline & $\mathrm{p}$ & .110 & .000 & .025 & .118 & . & .432 & .419 \\
\hline \multirow{2}{*}{ VG } & Korelasyon & $-.314^{*}$ & -.167 & .106 & -.031 & -.101 & 1.000 & $.261 *, * *$ \\
\hline & $\mathrm{p}$ & .012 & .190 & .407 & .810 & .432 & . & .039 \\
\hline \multirow{2}{*}{ İŞZ } & Korelasyon & $.422 * *$ & $-.083 *$ & .225 & .051 & -.104 & $.261 *$ & 1.000 \\
\hline & $\mathrm{p}$ & .001 & .517 & .076 & .693 & .419 & .039 & . \\
\hline
\end{tabular}

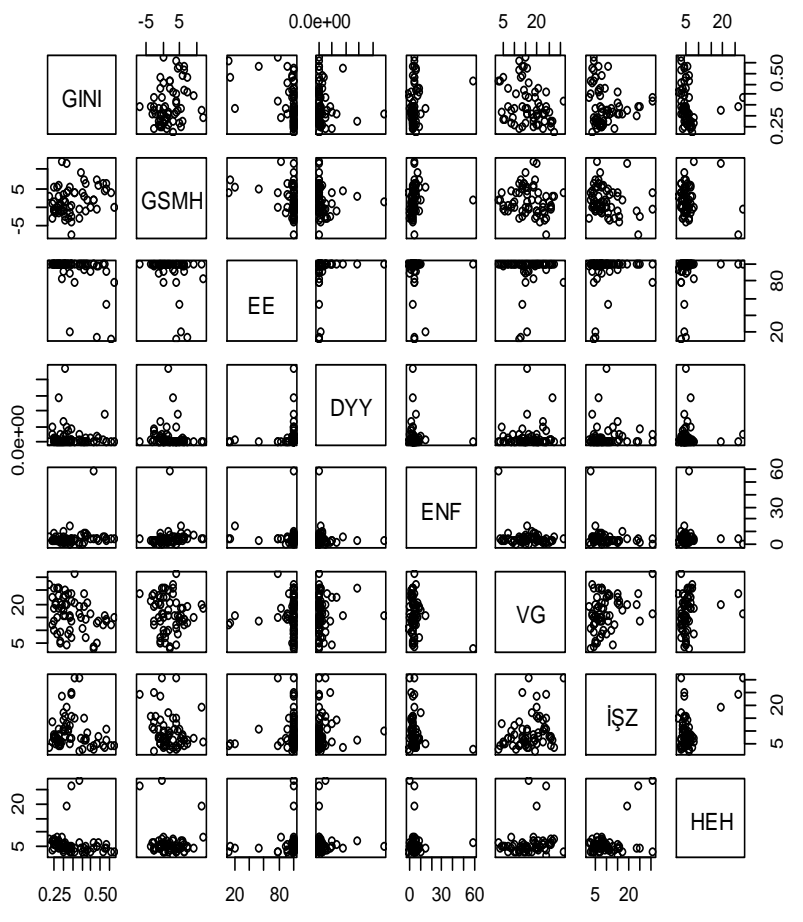

Şekil 1. Değişkenlere ilişkin serpilme diyagramı.
Şekil 1' de veri setinde yer alan makro ekonomik değişkenlere ait serpilme diyagramı verilmiştir. Serpilme diyagramına göre bağımlı değişken GİNİ katsayısı ile bazı diğer değişkenler arasında doğrusal bir ilişki görülmektedir. Serpilme diyagramına göre bağımsız değişkenler arasında kuvvetli ölçüde bir ilişki gösterecek doğrusallık yoktur.

Tablo 3. Link fonksiyonlarına ilişkin bilgi kriteri değerleri.

\begin{tabular}{lll}
\hline Bağ fonksiyonu & AIC & BIC \\
\hline Logit & -129.3951 & -110.1069 \\
Probit & -129.4447 & -110.1565 \\
Clog-log & -129.1753 & -109.8871 \\
Cauchit & -129.1041 & -109.8158 \\
Log & -128.9459 & -109.6577 \\
Log-log & -129.7334 & -110.4452 \\
\hline
\end{tabular}


Korelasyon analizi ve serpilme diyagramına göre GİNİ katsayısı bağımlı değişken alınarak regresyon modeli kurulabileceği sonucuna ulaşıldı. GINİ katsayısı 0-1 arasında yer alan oransal değerler içerdiği için, beta regresyon analizi uygulandı. Bağımlı değişken 0-1 aralığında değerler aldığı için beta dağılımı baz alınarak regresyon modeli kuruldu. Beta regresyon analizi kapsaminda toplam alt1 farklı bağ fonksiyonu kullanıldı. Tablo 3' te her bağ fonksiyonu için hesaplanan AIC ve BIC değerleri gösterilmektedir. Beta regresyon modelleri arasında AIC ve BIC değeri en düşük olan log-log bağ fonksiyonu tercih edildi. Tablo 4' te $\log -\log$ bağ fonksiyonu ile oluşturulan beta regresyon modeli sonuçları gösterilmektedir. $\mathrm{Bu}$ sonuçlara göre EE ve VG değişkenleri GİNi katsayısı üzerinde istatistiksel olarak anlamlı etkiye sahiptir $(\mathrm{p}<0.05)$. Genel olarak değerlendirildiğinde, $\mathrm{VG}$ ve $\mathrm{EE}$ değerleri arttıkça GİNİ katsayısı da düşmektedir. Buna göre VG ve EE değişkenleri ülkelerin gelir eşitsizliği üzerinde ters yönlü bir etki yapmaktadır.

\section{Sonuç ve Tartışma}

Yapılan çalışmada ele alınan 63 ülke için Gini Katsayı bağımlı değişken kabul edilerek bağımsız 7 makroekonomik değişken üzerinde Beta Regresyon analizi uygulanmıştır. Analiz sonuçlarına bakıldığında; Elektriğe Erişim ve Vergi Geliri değişkenlerinin Gini Katsayısı üzerinde istatistiksel olarak anlamlı olduğu açıkça görülmüştür. Yani, buradan edinilen bilgiye bakarak, Elektrik Erişimi ve Vergi Geliri ülkeler için arttıkça Gini Katsayısın da düşmeye sebep olacağı sonucu ortaya çıkmıştır.

\section{Teşekkür}

$\mathrm{Bu}$ çalışma 05-07 Ekim 2017 tarihinde düzenlenen 18. Uluslararası Ekonometri Yöneylem Araştırması ve İstatistik (EYİ 2017 Trabzon/Türkiye) sempozyumunda sözlü bildiri olarak sunulmuş ve bildiri özetleri kitabında yayınlanmıştır.

\section{Kaynaklar}

Anonim 2017.

http://databank.worldbank.org/data/ho me.aspx. Erişim Tarihi: 01.09.2017.

Atkinson, A.B. 1983. The Economics of Inequality 2nd Edition, Clarendon Press, Oxford.

Barro, R.J. 2000, Inequality and Growth in a Panel of Countries, Journal of Economic Growth, 5, 5-32.

Bronfenbrenner, M. 1971. Income Distribution Theory, Chicago, Aldine Atherton.

Carter, J.R. 2006, An Empirical Note on Economic Freedom and Income Inequality, Public Choice, 130, 163177.

Chong, A., Calderon, C. 2000, Institutional Quality and Income Distribution, Economic Development and Cultural Change, 48(4), 761-786.

Cribari-Neto, F., Souza, T. C. 2012. Testing inference in variable dispersion beta regressions. Journal of Statistical Computation and Simulation, 82, 18271843.

DPT 1994. Yedinci Beş Yı1lık Kalkınma Planı, Gelir Dağılımı ve Politikaları Özel İhtisas Komisyonu Raporu, Ankara, DPT Yayını, s. 1.

Ferrari, S., Cribari-Neto, F. 2004. Beta regression for modelling rates and proportions. Journal of Applied Statistics, 31(7), 799-815.

Li, H., Xu, L.C., Zou, H. 2000, Corruption, Income Distribution and Growth, Economics and Politics, 12(2), 155-182. 
McCullagh, P., Nelder, J. A., McCullagh, P. (1989). Generalized linear models, 2. London: Chapman and Hall.

Ospina, R., Ferrari, S. L. 2012. A general class of zero-or-one inflated beta regression models. Computational Statistics \& Data Analysis, 56, 1609-1623

Sen, A.K. 1973. On Economic Inequality, Oxford Universty Press, London.World Bank 2000, Attacking Poverty. Washington D.C.: World Bank Development Report.

Simas, A. B., Barreto-Souza, W., Rocha, A. V. 2010. Improved estimators for a general class of beta regression models. Computational Statistics \& Data Analysis, 54, 348-366.

Smithson, M., Verkuilen, J. (2006). A better lemon squeezer? Maximum-likelihood regression with beta-distributed dependent variables. Psychological methods, 11(1), 54.

Zhao, W., Zhang, R., Lv, Y., Liu, J. 2014. Variable selection for varying dispersion beta regression model. Journal of Applied Statistics. 41(1):95108. 